\title{
16
}

\section{CULTIVATING PRE-SERVICE AND IN-SERVICE TEACHERS' ABILITIES TO DEEPEN UNDERSTANDING AND PROMOTE LEARNING STRATEGY USE IN PUPILS}

\section{Tatsushi Fukaya and Yuri Uesaka}

\section{Summary}

Twenty-first-century skills education attempts to deepen understanding and promote effective learning strategies use among pupils. To accomplish this goal, we need to elucidate ways to enrich teachers' competencies. In this chapter, we introduce two practices to develop pre-service and in-service teachers' competence in promoting pupils' understanding and use of effective learning strategies. In the first practice, trainees in a university educational methods course experienced one-on-one tutoring (cognitive counseling) to assess and support learners who had difficulty in studying. In the second practice, elementary school teachers engaged in a new type of class called Thinking After Instruction (TAI) and lesson studies. We examined how these practices changed the teaching approaches employed by the in-service and pre-service teachers.

\section{Introduction: Two components of deeper learning}

One of the important goals of education in the 21st century is to foster a set of student educational outcomes collectively called deeper learning. This chapter focuses on deeper learning from two perspectives. In one aspect, deeper learning refers to profound understanding of learned concepts in a variety of disciplines. Structured content knowledge has long been recognized as an important component of academic ability which allows people to solve problems or make judgements efficiently and effectively (Bransford, Brown, \& Cocking, 1999).

In addition, recent educational research emphasizes the importance of helping students acquire competencies which are broader and more practical in society. This trend emerged in such concepts as key competencies (Rychen \& Salganik, 2003) and the 21st-century skills (Griffin, McGaw, \& Care, 2012). In this chapter, 
we focus on learning strategy as one of the important competencies. We chose to focus on learning strategy because the use of effective strategies promotes the acquisition of structured knowledge (Ainsworth, Prain, \& Tytler, 2011), and developing students' ability to learn by themselves is especially important to life in changing societies (Rychen \& Salganik, 2003).

\section{Importance of teacher education}

To promote students' deeper learning, we must address the following question: how can we foster teachers' abilities to deepen understanding and promote use of effective learning strategies in pupils? According to Darling-Hammond and Baratz-Snowden (2005), teacher education is an issue that must be addressed in order to practice effective teaching, and teachers' knowledge has been a point of interest as a factor which enables teachers to perform high quality teaching. In that context, pedagogical content knowledge (PCK), introduced by Shulman (1986), has been an important addition to research on professional teaching.

Shulman (1987) defined PCK as a "special amalgam of content and pedagogy that is uniquely the province of teachers, their own special form of professional understanding" (p. 8). Two components proposed by Shulman (1986) have been influential in this area (Depaepe, Verschaffel, \& Kelchtermans, 2013): knowledge of instructional representations and knowledge of learners. The former means knowledge used to explain subject contents effectively with analogies, illustrations, examples, or demonstrations. The latter refers to knowledge about students' procedural bugs and misconceptions. It also includes the knowledge used to judge whether students learn specific contents with ease or difficulty.

However, while PCK has successfully conceptualized teachers' ability to impart subject contents effectively, it seems to be failing to capture teachers' expertise to help pupils acquire more generic competencies such as learning strategy use. To solve this problem, Fukaya and Uesaka (2018) proposed knowledge of instructing learning strategy as a new component of teachers' knowledge. This corresponds to the base of teachers' knowledge to support students in mastering learning strategies through teaching specific subject content. On the basis of acknowledging the importance of cultivating children' generic competencies as mentioned above, we need to develop ways to assess and enrich teachers' knowledge to promote not only deep understanding, but also pupils' ability to use learning strategies.

\section{The framework of this chapter}

To develop teachers' competency in promoting pupils' understanding and use of learning strategies, we have to enrich the quality of teacher education both for pre-service and in-service teachers. Recent educational research and policies assume that teachers develop their professional ability all through their work life (e.g., OECD, 2005). We assume that engaging in practical teaching activities 
based on educational theories during both pre-service and in-service stages is effective to promote lifelong learning in teachers. Therefore, we conducted practices for pre-service teachers (Practice 1) and for in-service teachers (Practice 2). It is also important to note that although two practices were conducted for different participants (pre-service teachers, and in-service teachers) in different contexts (a university methods course and elementary school classes), both practices attempted to improve teaching methods focusing on students' deep understanding and effective learning skills.

Practice 1 explored the effects of learning and experiencing cognitive counseling in a university course (details of this study were reported in Fukaya \& Uesaka, 2017). Cognitive counseling is a research activity in which counselors (usually educational researchers or school teachers) assess clients' (usually students) problems in learning and teach the client to solve those problems thorough individual consultations (Ichikawa, 2005). Cognitive counseling has a basis in cognitive theory; that is why counselors focus on students' problems from the perspective of understanding, metacognition, and learning skills. Although we usually conduct individual consultations from five to ten times or more in cognitive counseling, it is difficult to provide university students with such opportunities in a regular educational method course. Therefore, we required students to conduct a counseling session only once as a homework assignment.

On the other hand, Practice 2 focused on in-service teachers. In Practice 2, teachers in a public elementary school in Japan engaged in practices to improve math classes over a period of two years, introducing a teaching approach called Thinking after Instruction (TAI); this practice was reported in Fukaya, Uesaka, Ota, Koizumi, \& Ichikawa, 2017. TAI is intended to promote students' deep understanding and learning strategy use through changing teachers' ways of designing classes. To achieve this aim, our research group worked with teachers together to design lesson plans and did lesson studies (explained in detail in a later section).

\section{Practice 1}

\section{Description of the practice}

This practice examined the effects of learning cognitive theory and experiencing cognitive counseling on pre-service teachers' knowledge of teaching. The participants were 102 students in a pre-service teacher training program who attended an educational methods course at a national university in Japan and provided consent for study participation. The course consisted of 15 class sessions. Because this course addressed educational methods for elementary and secondary education in general, we handled a variety of subjects like mathematics, science, and social studies. The first half of the course (first to eighth class sessions) was directly related to cognitive counseling. We describe that below, dividing the contents into three parts. 


\section{Initial stage of the practice}

The purpose of the initial stage of the course was to understand an educational goal: attaining deep understanding and mastering learning strategies. For example, the class sessions dealt with topics like understanding (in the second class session), metacognition (third class session), and motivation (fourth class session). In the first class session, the teacher (first author) explained the course goal: to acquire knowledge and skills to support pupils' learning in a variety of contexts based on cognitive theory. The students would be required to conduct one-on-one tutoring as an opportunity to practice what they were learning, and to write a report summarizing the outcomes as a homework assignment.

The theme of the second class session was types of knowledge. Students first learned the distinction between rote memorized knowledge and deeply understood knowledge. Research in cognitive theory demonstrates that understanding a principle or meaning behind a procedure or rule promotes memory, knowledge transfer, and motivation (e.g., Bransford et al., 1999), while rote memorized knowledge is easy to forget and difficult to apply in other contexts. In the class, students participated in actual memory experiments as demonstrations. Students then discussed how they would explain concrete subject contents if they were teachers trying to promote pupils' understanding.

In the third class session, students learned about metacognition, particularly focusing on conceptions of learning and learning strategy. To explain conceptions of learning, we emphasized that it is important for students to have conceptions that are understanding (not rote) oriented, process (not result) oriented, and quality (not quantity) oriented (e.g., Ichikawa, 2005). Students were also instructed in three types of learning strategies (cognitive strategy, metacognitive strategy, and external resource strategy; cf. Pintrich, Smith, García, \& McKeachie, 1993) with examples or demonstrations in various disciplines. Finally, they discussed in groups how they could help junior high school students learn effectively.

\section{Middle stage of the practice}

During this stage, the pre-service teachers learned how they could enhance students' academic ability. We particularly focused on the basic skills of cognitive counseling in the fifth and sixth classes, and students conducted an actual counseling session outside of the class.

The topic of the fifth class was the basic procedures of cognitive counseling. In cognitive counseling, three perspectives of assessment for pupils' difficulty with learning a subject were emphasized: knowledge, learning strategy, and conceptions of learning. To effectively assess a pupil's difficulty, four counseling techniques were introduced: a) asking pupils to explain their thoughts, b) explaining concepts with diagrams, c) requiring pupils to explain what they learned (checking their comprehension), and d) prompting pupils to extract important points (lesson induction; e.g., Ichikawa, 2005). The teacher then showed a brief report 
of an actual case in which a fifth-grade pupil incorrectly solved the problem of "What is the area of $20 \mathrm{~m}^{2}$ in $\mathrm{cm}^{2}$ ?" (her answer was 2,000 $\mathrm{cm}^{2}$ ). After students discussed what difficulty she faced and how to support her if they were counseling, the teacher summarized the important points: teachers should assess pupils' difficulty not only at the knowledge level (i.e., she confused area with length), but also at the learning strategy level (i.e., she did not draw a diagram spontaneously), and support strategy use by, for example, requiring the pupil to explain their thoughts with diagrams or promoting their awareness of strategy use as a resource for understanding.

\section{Final stage of the practice}

Students conducted an individual counseling after the fifth class and submitted a brief report in the seventh class. In the eighth class, a representative student gave a presentation about her report, in which she conducted a counseling session with a 10th-grade high-school girl who incorrectly solved a word problem involving a quadratic function. After the representative student presented her report, the class discussed what was good in the report and how she could improve her counseling session. They then considered how they might improve their own counseling session and written report. Because they could again realize the importance of deep understanding and strategy instruction through the representative report, they made comments such as "I should emphasize the meaning of the formula, not only giving the knowledge" and "I should ask my student after solving the problem what he should do to avoid the same mistake."

\section{Measurements}

We conducted a pre-test in the first class and a post-test in the eighth class through a tutoring scenario method. In this method, a description was provided of a girl who had difficulty in understanding and incorrectly solved a concrete mathematical problem (Fukaya \& Uesaka, 2018). Students described how they would respond to the hypothetical tutoring situation. The scenarios consisted of two types of material; the first one was addition of fractions (the pupil's incorrect answer was $1 / 2+1 / 3=2 / 2=1$ ), and the second one was calculating the area of complex circles (see Fukaya \& Uesaka, 2017, for details). Participants who worked on the fraction problem at pre-test worked on the circle problem at posttest, and vice versa. Both tests were conducted during the class.

Post-tests included additional questions to check the meaning of what participants described. We hypothesized that the number of descriptions about comprehension checking and strategy instruction would increase. Therefore, we asked the following additional two questions and had students write responses as concretely as possible: a) "How do you confirm the pupil's understanding after you counsel her?" and b) "What kind of points do you want her to write if you ask her to extract lessons from this problem?" The first question concerned the level 
of checking (understanding of mathematical procedures or concepts) and the second concerned the level of lessons (lessons on knowledge or learning strategy).

\section{Results and discussion}

\section{Coding procedure}

The number of participants who responded to the fraction problem was 51 at pre-test and 53 at post-test, and those who responded to the circle problem were 51 at pre-test and 46 at post-test. The data of seven participants were excluded from the data analysis, because they erroneously responded to the same task at pre- and post-tests.

All descriptions were classified into corresponding categories according to the following perspectives: assessment, explanation, comprehension checking, and strategy instruction. With respect to assessment, for example, the descriptions were classified into four categories: no assessment, abstract description, questioning, and analyzing. The first author coded all descriptions based on the schema. Then, after training, a graduate student majoring in educational psychology also coded all data. We computed kappa coefficients with respect to each perspective and deemed inter-rater agreement satisfactory $(M=.81)$.

We then defined effective assessing and teaching strategies based on specific criteria. Assessment was considered effective when the student intentionally assessed the cause of the pupil's mistake (questioning and analyzing). We deemed conceptual explanation (explaining to the pupil the meaning of the mathematical procedure) effective when the student explained the concept or reason behind the procedure that the pupil had misunderstood. Comprehension checking was classified effective when the student required the pupil to explain the problem to confirm whether they understood the meanings behind the procedures (requiring explanation). Strategy instruction was deemed effective when those descriptions included statements to promote use of learning strategies in students (explicit instruction and inducing lessons).

\section{Comparison between pre- and post-tests}

A Mann-Whitney $U$ test was conducted on each problem and perspective, in which time (pre- or post-test) was treated as an independent factor. With the fraction problem, we found significant differences in assessment $(z=3.20, p<.01)$, comprehension checking $(z=4.84, p<.01)$, and strategy instruction $(z=3.52, p<.01)$, indicating that participants provided more effective descriptions at post-test than they did at pre-test (Figure 16.1). For conceptual explanation, the difference between pre- and post-tests did not reach statistical significance. The same analysis was conducted with the circle problem. Those results showed that the post-test ratios of effective descriptions were higher than the pre-test ratios on assessment $(z=3.46, p<.01)$, comprehension checking $(z=5.75, p<.01)$, and strategy 


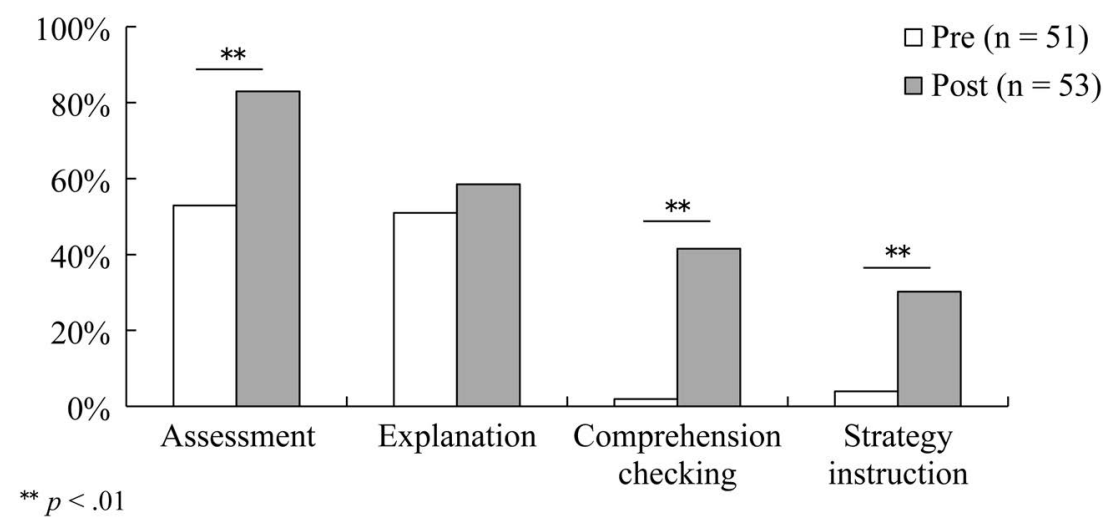

FIGURE 16.1 Ratios of descriptions representing effective teaching in fraction problem.

instruction $(z=4.44, p<.01)$ (Figure 16.2). Although the post-test ratio on conceptual explanation was higher in descriptive terms, the difference did not reach statistical significance $(z=1.66, p=0.97)$.

Even though the pupil's answer clearly indicated that she did not understand the rationale of the solution to the problem, pre-service teachers did not at first make inferences or ask what she misunderstood; however, throughout the course, they seemed to increasingly pay attention to pupils' deep understanding. In fact, we found that the post-test ratio of effective assessment was higher than the pre-test ratio by almost 30\%. We also found that almost none of the pre-service teachers provided effective descriptions of comprehension checking and strategy instruction in the pre-test. However, after learning in the course and experiencing cognitive counseling outside of class, effective descriptions of comprehension checking and strategy instruction increased greatly at the post-test.

On the other hand, we did not find any significant difference in conceptual explanation. This might be due to the fact that participants would need more

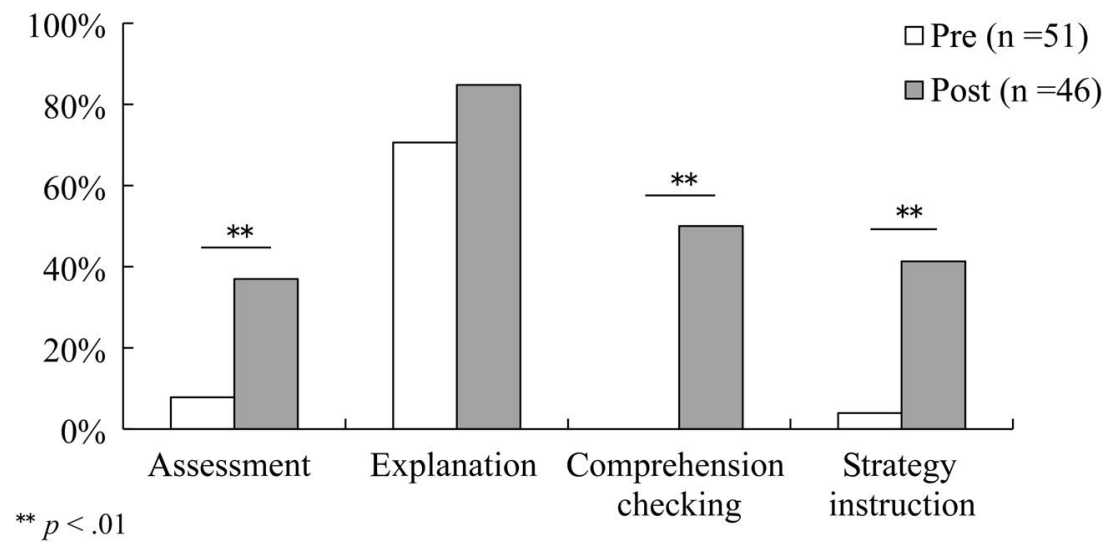

FIGURE 16.2 Ratios of descriptions representing effective teaching in circle problem. 
subject expertise to provide conceptual explanations compared to other perspectives (Inoue, 2009). However, the post-test ratios in conceptual explanation were higher as descriptive values than the pre-test ratios in both tasks, so that students could possibly provide conceptual explanations with longer term training. Further research should be carried out to investigate whether pre-service teachers can acquire the ability to explain the meaning behind mathematical procedure by training in cognitive counseling.

In practice 1, pre-service teachers not only learned a variety of concepts in cognitive theory and procedures of cognitive counseling but also performed actual cognitive counseling outside of the class as an opportunity to practice what they learned in the course. In addition, they learned from actual cases including a report presented by a representative student and reflected on how they could improve their own counseling and reporting. The results of the tutoring scenario method suggest that participants acquired skills to assess a pupil's state of knowledge and promote understanding and learning strategy use, although these results, which did not evaluate actual teaching behavior, were preliminary in nature.

\section{Practice 2}

\section{Description of the practice}

Pupils' deep understanding and acquisition of effective learning strategies could be achieved mainly through daily classes in schools. Therefore, it is important to provide training for in-service teachers to improve the quality of lessons. In this practice, we introduced an approach centered on Thinking after Instruction (TAI). TAI, proposed by Ichikawa (2004), is a framework used to design classes in a variety of subjects, in which direct instruction from a teacher and discovery learning of pupils are combined with activities to promote pupils' metacognition (Fukaya, Uesaka, \& Ichikawa, 2018; Ichikawa, Uesaka, \& Manalo, 2017).

TAI consists of four phases: (a) teacher's instruction, (b) comprehension checking, (c) deepening understanding, and (d) self-evaluation. First, teachers give direct instruction on basic content focusing on meanings or principles, which enable pupils to elaborate facts, concepts, or formulas. Even after a teacher provides direct instruction, however, pupils might not understand the concepts. In comprehension checking, pupils are required to check their understanding by, for example, working in pairs to explain what the teacher explained. In the third step, the teacher provides a task to deepen pupils' understanding. The task is designed to require them to apply what they had learned in the class or resolve their remaining misconceptions, and pupils try to discover those solutions in collaborative groups with other classmates. In self-evaluation, pupils reflect on what they understood and what they did not understand in the class.

One of the characteristics of TAI is an emphasis on pupils' deep understanding. Direct instruction from a teacher must focus on meaning, rationales, or relationships, not just pronouncing isolated facts or formulas (Ichikawa et al., 2017). 
After instruction, pupils are required to check their comprehension by explaining the teacher's lesson in their own words. The explanation activities make them aware of whether they really understand the material (Fukaya, 2013). In deepening understanding, pupils engage in solving more advanced problems. This is important because pupils often do not fully understand the content or fail to apply knowledge in other contexts (e.g., Renkl, Mandl, \& Gruber, 1996).

Another important characteristic of TAI is that teachers elaborate explanations and set activities to promote pupils' use of effective learning strategies (Ichikawa et al., 2017). For example, one such learning strategy is to draw diagrams. Although many studies have demonstrated that drawing diagrams is an effective strategy to solve problems or learn concepts efficiently (e.g., Ainsworth et al., 2011), some pupils have difficulty in using diagrams spontaneously and effectively (e.g., Uesaka \& Manalo, 2017). In TAI, teachers set up opportunities to prompt pupils to use diagrams in classes. For example, teachers give direct instruction using diagrams to represent the structure or meaning of the problems as a model for explanation. In the following phases, such as comprehension checking and deepening understanding, pupils are required to use diagrams actively when they solve problems and explain their thoughts to others.

In practice 2 (reported in detail in Fukaya et al., 2017), teachers in a public elementary school in Japan adopted TAI on a daily basis to design mathematics classes for two years. In this school, other interventions such as lesson study, a three-way review, and corroboration with external researchers (i.e., the authors) were also implemented as detailed below. The wide range of interventions used in this educational practice made it difficult to specify with certainty which of those interventions affected the dependent variables. However, it was important to investigate if these interventions, centered on TAI, improved pupils' academic ability and teachers' skills at teaching, especially in general terms (i.e., not limited to specific topics). Of course, we were not expecting that the effects of the interventions would transfer to other subjects in an unlimited manner (cf. Barnett \& Ceci, 2002), but we predicted that teachers could design effective TAI classes dealing with mathematical topics, which some of them do not teach directly in their classes, after the interventions.

\section{Email exchanges preceding a lesson study class}

Teachers in each grade in the school conducted lesson study once a year. Lesson study is an educational method of improving teaching quality conducted widely in Japanese schools. In lesson study, a representative teacher conducts a class, and other teachers, including the school principal and external participants (in this case, the authors) observe. Afterward, teachers and participants get together and discuss the class in an open format (see Lewis, Perry, \& Murata, 2006, for more detail about lesson study).

Prior to a lesson study, teachers and researchers exchanged emails to explain the details of the practice. Although TAI is assumed to be a powerful 
framework for designing classes that promote pupils' understanding and use of effective learning strategies, at first, the quality of the lesson plans that teachers made was not good enough. For example, a lesson in sixth-grade in the first semester of the first year concerned the topic of $x$ times and proportion. The problem in the textbook was like this: A pupil played basketball. Her number of successful shots in three games increased from $30 \mathrm{in} 5$ th-grade to $50 \mathrm{in} 6$ th-grade. How many times is the number of successful shoots in 6th-grade compared to the number in 5th-grade? At first, teachers planned to show a formula for "the amount compared $\div$ the amount referred $=$ proportion $(x$ times $)$ " and explain how to apply the formula to the problem.

Via email, both the first and second authors separately pointed out that the plan did not seem to emphasize pupils' understanding of the meaning behind the formula. The first author pointed out, "In the plan, it seems that the teachers are just showing the formula and having pupils put the problems into that formula. I am worried that pupils will learn the procedure without understating the meaning through that explanation." We also proposed alternative ideas to teachers. The second author suggested the following idea: "The important point of this topic is the idea of viewing the amount referred to as a referential part. ...If I were a teacher, I would show three lengths $(10 \mathrm{~m}, 50 \mathrm{~m}$, and $25 \mathrm{~m})$, and explain that if I view $10 \mathrm{~m}$ as a referential part, then $50 \mathrm{~m}$ is 5 times and $25 \mathrm{~m}$ is 2.5 times, but if I view $50 \mathrm{~m}$ and $25 \mathrm{~m}$ as a referential part, then $10 \mathrm{~m}$ is $1 / 5$ and 10/25 (2/5) times more, respectively..."

Of course, teachers did not have to adopt our ideas, but, through discussions, we (teachers and researchers) gradually shared the goals which TAI aims to achieve. In actual classes, teachers changed their plans and carefully explained the point of reference using diagrams.

\section{An example of lesson study and discussions}

We also briefly showed an example of a lesson study and subsequent discussions. In the 6th-grade class in the second year, a lesson study on speed was conducted. In the lesson study class, the teacher used the following task: which is faster, a red car driving $300 \mathrm{~km}$ in 3 hours or a blue car driving $250 \mathrm{~km}$ in 2 hours? The teacher first explained that we can compare speeds by distance per hour. In his explanation, the relationships between speed, time, and distance were emphasized using two blocks representing two cars' distance and hours, not just telling pupils the formula. In comprehension checking, pupils solved similar problems by drawing number lines, and explained their thoughts in pairs using the drawn diagrams. In deepening understanding, three types of problems were shown: a) a problem asking about speed, b) a problem asking about distance, and c) a problem asking about time. Pupils drew number lines and explained, in groups, how they could work out the answer.

After the class, all the teachers got together and had group discussions using a three-way review approach. In the three-way review, teachers in small groups (three to six participants in each group) reflected on the class from three 
perspectives: a) good points, b) points for improvement, and c) points that could be used in other units or subjects (Uesaka, Fukaya, \& Ichikawa, 2017). Each group then presented their summarized comments to share ideas. In the discussions, several groups pointed out that while the teacher's instruction using diagrams was effective to help pupils understand the relationship between speed, time, and distance, some pupils have difficulty in drawing and explaining the diagrams in the following phases. The external researchers commented that teachers should demonstrate a model of explanation by, for example, showing pupils how to represent and explain number lines. Through these discussions, teachers understood the concepts of deep understanding and learning strategy and how to design effective TAI classes.

\section{Measurements}

To verify the effects of the interventions, we collected three kinds of data (two for pupils and one for teachers) in the first semester of each year. Although the effects of interventions would emerge most strongly in the final semester in the second year, we had to report the results at a school conference in November in the second year, so we conducted investigations in the first semester (rather than the second semester) of that second year.

The first set of data was taken from the National Assessment of Academic Ability, which is conducted annually for sixth-grade pupils in Japanese elementary schools. This test consists of mathematics and Japanese, so we examined if test performance in the second year improved only in mathematics, not in Japanese (see National Institute for Educational Policy Research, 2013, 2014 for actual test items). The second set of data was from a learning strategy test, which examined the degree to which pupils used diagrams while solving word problems. Two test sets were prepared. In each set, four word problems were shown with space under each problem. In the space, we required pupils to write their thoughts in words, formula, and/or diagrams. In the third data set, teachers' knowledge was examined through lesson plan tasks. Teachers wrote a lesson plan for an hour on the formula of the area of a trapezoid or line symmetry based on TAI. With a copy of a textbook, about half of the teachers made a plan for teaching the trapezoid material in the first year, and a plan for teaching the line symmetry material in the second year (and vice versa). The data were taken from all teachers who teach mathematics. The total number of participants was 100 6th-grade pupils and 20 teachers in the first year, and 111 pupils and 17 teachers in second year.

\section{Results and discussion}

\section{National Assessment of Academic Ability}

First, we computed $z$ scores based on national average scores in each year. There were also two types of problems (A or B); while type A consisted of basic problems, type B comprised applied problems. We analyzed each type of test. We conducted 


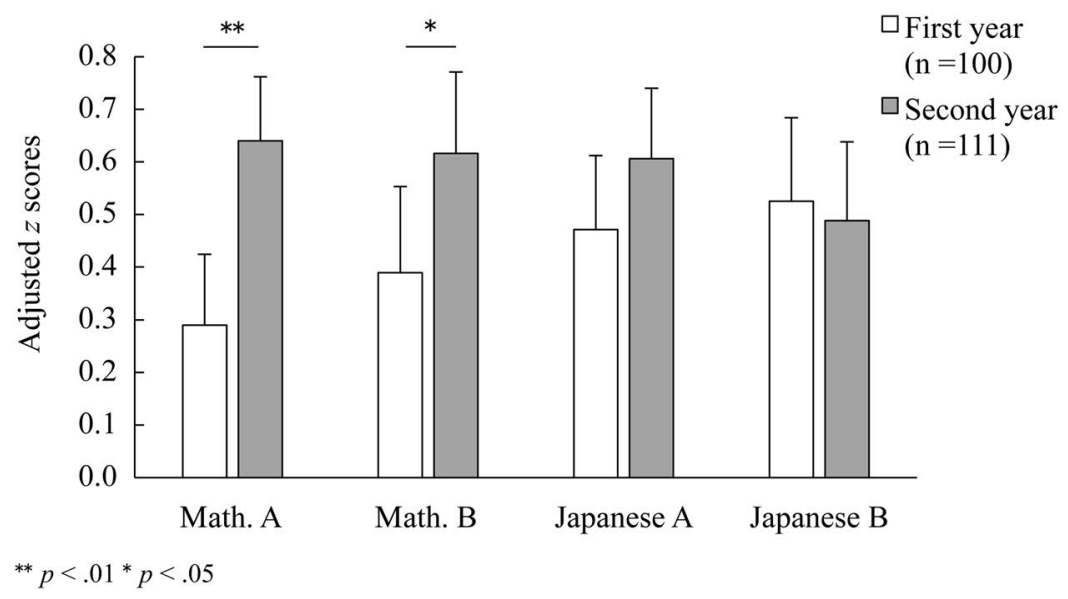

FIGURE 16.3 Test performance of national assessment of academic ability. Error bars represent $95 \%$ confidence intervals.

ANCOVAs with two variables as covariates (self-reported pre-achievement on report cards and whether they go to cram school). The results in Figure 16.3 show that the effects of time (first versus second year) were statistically significant only in mathematics, demonstrating that test scores in the second year were higher than those in the first year $(t(207)=3.64, p<.001$ in mathematics $\mathrm{A}, t(207)=1.96, p<.05$ in mathematics B). In addition, the degree of $S D$ (a measure of spread or variation) in the second year in mathematics $A(S D=.60)$ was smaller than that in the first year $(S D=.88)(F(1,209)=5.54, p=.02)$, indicating that differences between individuals in math test performance decreased in the second year. In contrast, the differences in scores on the Japanese test were not statistically significant.

\section{Learning strategy test}

The first author scored answers and coded whether pupils drew diagrams. Interrater reliabilities with a trained undergraduate student were high both in test scores (95\%) and use of diagrams (89\%). We conducted an ANCOVA to examine the effects of time and task set with two covariates. For the number of problems with incorrect answers without diagrams, the effect of time was statistically significant $(F(1,199)=12.65, p<.001)$. There was no other significant main effect or interaction. For the number of problems of correct answers with diagrams, the effect of time was also statistically significant $(F(1,199)=9.31$, $p<.01)$. Again, there was no other significant main effect or interaction. As shown in Figure 16.4, the results demonstrate that while the number of problems with incorrect answers without diagrams in the first year was higher than that in the second year, the number of problems with correct answers with diagrams in the second year was higher than that in the first year. The results suggest 


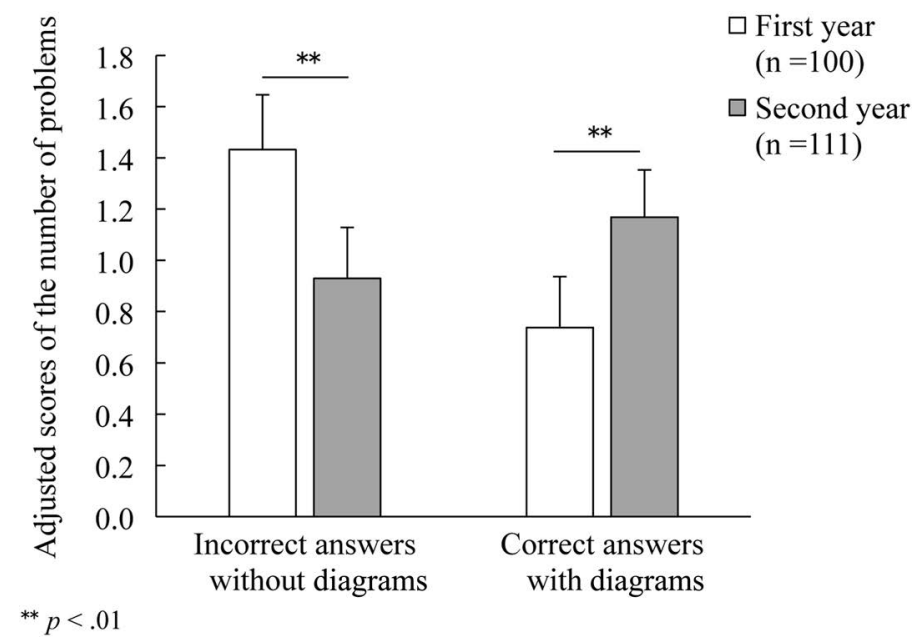

FIGURE 16.4 The number of problems with incorrect answers without diagrams and correct answers with diagrams. Error bars represent 95\% confidence intervals.

that pupils in the second year more often drew diagrams spontaneously when solving word problems, which helped lead them to correct answers, compared to pupils in the first year.

\section{Lesson plan task}

One hypothesis to explain the increase of academic performance in pupils is that teachers' way of designing mathematics classes had changed. Teachers in the second year might have designed more effective TAI than those in the first year. To verify this hypothesis, we examined if there were differences between lesson plans in the first and second years. In the analysis, we coded descriptions of teachers' instruction, comprehension checking, and deepening understanding. Based on previous research and practices (e.g., Depaepe et al., 2013), we coded the existence of descriptions representing effective teaching in each phase. For example, we coded whether teachers explained rationales of formulae or relationships between concepts and gave instructions that took pupils' misconceptions into account. Comprehension checking and deepening understanding were also measured by, for instance, noting whether the tasks focused on rationales of relationships or pupil's misconceptions and whether teachers set opportunities for pupils to explain their thoughts in pairs or groups.

To compare total average scores of the lesson plan task between the first and second years, we conducted an ANOVA with the difference of academic year and task (trapezoid or line symmetry) as independent variables and coded scores of lesson plans as a dependent variable. The results showed that while the task had a significant effect $(F(1,33)=22.71, p<.01)$, the difference of academic year 
showed only a marginally significant effect $(F(1,33)=3.35, p=.08)$. Although the difference of academic year did not reach significance due to the limited sample size, the scores on the lesson plan task in the second year were higher than those in the first year in both types of problems (for area of trapezoid, $M=5.80$ in the first year and $M=6.43$ in the second year; for line symmetry, $M=7.10$ in first year and $M=8.30$ in second year).

Practice 2 examined whether interventions centered on TAI have an impact on pupils' academic ability and teachers' mathematics classes. Here, we discussed how these interventions might have changed teachers' ways of teaching, and pupils' ways of learning. First, the results of the lesson plan task indicated that teachers developed an ability to design effective TAI classes. For example, the descriptions about setting pair or group work in comprehension checking and deepening understanding increased from $48 \%$ (first year) to 59\% (second year) in total. Setting pair or group work possibly enhanced pupils' diagrams use, because using diagrams is effective for pupils to communicate their thoughts in pair and group work. In fact, Uesaka and Manalo (2017) argued that explanation activities in pairs or groups promote subsequent spontaneous use of diagrams during individual problem solving. The results of the learning strategy test, which demonstrated pupils could use diagrams as tools to grasp meanings and structures of mathematical concepts in the second year, also support this conjecture.

Second, the results of analyzing the teachers' lesson plan task suggest that teachers came to emphasize conceptual meanings behind procedures and take into account pupils' misconceptions in their instructions and task setting in the second year. As we described in the section on "Description of the practice," teachers at first designed lesson plans which focused on procedural memorization rather than conceptual understanding of what's behind the procedure. But they gradually realized how they could promote mathematical understanding and resolve misconceptions in pupils. These changes in classes likely led to pupils' acquisition of structured, usable knowledge. In fact, the results of the National Assessment of Academic Ability demonstrated that pupils in the second year attained higher achievement on basic and applied knowledge tests in mathematics. Individual differences in the type A mathematics test also decreased in the second year. As such, teachers' changes in designing TAI mathematical classes could possibly influence pupils' use of learning strategies and knowledge acquisition.

\section{General discussion}

As described at the beginning of this chapter, it is important for learners to acquire both structured subject knowledge and more generic competencies in 21st-century environments. These competencies include, for example, learning strategies. Students need to master how to learn effectively though school education because, in rapidly changing societies, they have to keep their knowledge updated after they graduate from schools. It is, therefore, important to cultivate 
teachers' competencies to promote not only deep understanding of contents but also acquisition of effective learning strategies in pupils. This chapter introduced two practices aimed at enhancing teachers' knowledge of teaching strategies. Although the two practices we introduced were different in contents, participants, and approaches, they shared an emphasis on the same educational goals and methods for strengthening pupils' knowledge base and competencies (e.g., setting up explanation activities with diagrams).

One of the distinctive features of the two practices is their conceptualization of knowledge about instructing learning strategies as knowledge that pre-service and in-service teachers must develop. Previous research on teachers' knowledge such as PCK has focused on knowledge of instructional representations and knowledge of learners (Depaepe et al., 2013; Shulman, 1986, 1987). Of course, these components are still important to help pupils become aware of their own misconceptions and lack of knowledge, and to effectively support knowledge acquisition. If teachers, however, can successfully impart subject knowledge to pupils, it does not mean that they can successfully help pupils acquire the ability to learn by themselves. Although many interventions using PCK have been conducted, those interventions mainly concerned knowledge for teaching specific subject matter (see Depaepe et al., 2013, for a review). Considering the increasing recognition of the importance of generic skills (Griffin et al., 2012; Rychen \& Salganik, 2003), teacher education focusing on nurturing pupils' generic skills has also been emphasized in this study.

Although two practices reported in this chapter demonstrated the effects of interventions based on cognitive counseling and TAI, several important issues remain unanswered. First, in both practices, teachers' knowledge for teaching was evaluated using paper-based assessments (tutoring scenario method in practice 1 , and lesson plan task in practice 2). We assume that these assessments partly reflect actual teaching behavior, but more rigorous and multifaceted verifications would be needed to capture more accurate data about teachers' knowledge for teaching. In actual teaching situations, teachers would need to check and flexibly adjust to pupils' responses, so it is not guaranteed that teachers could conduct their teaching as they planned. Therefore, further research should be conducted to examine how classroom teaching using teachers' knowledge changes in practice, for example, by observing actual mathematics classes.

Second, because pre-service teachers had limited experience of cognitive counseling in practice 1 , long-term commitment in actual cognitive counseling would be needed in future research. In actual cognitive counseling, we conducted individual tutoring sessions for a higher number of sessions (usually five to ten times) in order to cultivate pupils' acquisition of knowledge and learning skills (Ichikawa, 2005). In an ongoing research project in Hiroshima University, we have provided opportunities for pre-service teachers to conduct cognitive counseling to elementary school pupils over a longer term. In that project, about 40 pre-service teachers learned cognitive theory and are practicing cognitive counseling for four years. Thus, we plan to examine how the long-term practice 
of cognitive counseling influences knowledge for teaching of pre-service teachers in a future study.

Third, the findings of practice 2 were based on a limited sample and measurements. Participants were only 6th-grade pupils, and the practice was conducted in only one school. Furthermore, we have to verify whether interventions based on TAI have impact on learning strategies other than drawing diagrams. For example, pupils in pairs check their comprehension by explaining what a teacher instructed in comprehension checking in TAI. This explaining activity may strengthen pupils' awareness of the effectiveness of the explanation strategy, because they realize that they can check their own understanding by explaining what they learned to others. Hence, TAI research targeting a variety of learning strategies would be an interesting direction in future research.

\section{References}

Ainsworth, S., Prain, V., \& Tytler, R. (2011). Drawing to learn in science. Science, 333, 1096-1097.

Barnett, S. M., \& Ceci, S. J. (2002). When and where do we apply what we learn? A taxonomy for far transfer. Psychological Bulletin, 128, 612-637.

Bransford, J. D., Brown, A. L., \& Cocking, R. (1999). How people learn: Brain, mind, experience, and school. Washington, DC: National Academy Press.

Darling-Hammond, L., \& Baratz-Snowden, J. C. (2005). A good teacher in every classroom: Preparing the highly qualified teachers our children deserve. San Francisco, CA: Jossey-Bass.

Depaepe, F., Verschaffel, L., \& Kelchtermans, G. (2013). Pedagogical content knowledge: A systematic review of the way in which the concept has pervaded mathematics educational research. Teaching and Teacher Education, 34, 12-25.

Fukaya, T. (2013). Explanation generation, not explanation expectancy, improves metacomprehension accuracy. Metacognition and Learning, 8(1), 1-18.

Fukaya, T., \& Uesaka, Y. (2017). Kobetsu shien no jissen taiken wo toriireta kyoin yousei katei no jyugyo jissen (Educational practice to enhance teacher trainees' practical abilities for learning support through the experience of Cognitive-Counseling). Japan Journal of Educational Technology, 41, 157-168.

Fukaya, T., \& Uesaka, Y. (2018). Using a tutoring scenario to assess the spontaneous use of knowledge for teaching. Journal of Education for Teaching, 44, 431-445.

Fukaya, T., Uesaka, Y., \& Ichikawa, S. (2018). Investigating the effects of Thinking after Instruction approach: An experimental study of science class. Educational Technology Research, 41, 1-11.

Fukaya, T., Uesaka, Y., Ota, Y., Koizumi, K., \& Ichikawa, S. (2017). Tishiki no syutoku, katsuyo, oyobi gakusyu houryaku ni shouten wo ateta jygyo kaizen no torikumi (Improving students' performance in an elementary mathematics class: Focusing on students' knowledge acquisition, utilization, and learning strategies using a "Thinking After Instruction" Approach) [In Japanese with English abstracts]. The Japanese Journal of Educational Psychology, 65, 512-525.

Griffin, P., McGaw, B., Care, E. (2012). Assessment and teaching of 21st century skills. Dordrecht, The Netherlands: Springer.

Ichikawa, S. (2004). Manabu iyoku to sukiru wo sodateru (Fostering motivation and skill to learn: Strategies for improvement in academic ability). Tokyo, Japan: Shogakukan. 
Ichikawa, S. (2005). Cognitive counseling to improve students' metacognition and cognitive skills. In D.W. Shwalb, J. Nakazawa, \& B. J. Shwalb (Eds.), Applied developmental psychology: Theory, practice, and research from Japan (pp. 67-87). Greenwich, CT: Information Age.

Ichikawa, S., Uesaka, Y., \& Manalo, E. (2017). Three approaches to promote spontaneous use of learning strategies. In E. Manalo, Y. Uesaka, \& C. A. Chinn (Eds.) Promoting spontaneous use of learning and reasoning strategies: Theory, research, and practice for effective transfer (pp. 195-210). London: Routledge.

Inoue, N. (2009). Rehearsing to teach: Content-specific deconstruction of instructional explanations in pre-service teacher training. Journal of Education for Teaching, 35, 47-60.

Lewis, C., Perry, R., \& Murata, A. (2006). How should research contribute to instructional improvement? The case of lesson study. Educational Researcher, 35, 3-14.

National Institute for Educational Policy Research. (2013). Heisei 25 nendo zenkoku gakuryoku gakusyu jyokyo chosa no chosa mondai, seitou rei, kaisetsu siryo ni tsuite (Test items, examples of correct answer, and commentaries of national assessment of academic ability in 2013). Retrieved from http://www.nier.go.jp/13chousa/13chousa.htm

National Institute for Educational Policy Research. (2014). Heisei 26 nendo zenkoku gakuryoku gakusyu jyokyo chosa no chosa mondai, seitou rei, kaisetsu siryo ni tsuite (Test items, examples of correct answer, and commentaries of national assessment of academic ability in 2014). Retrieved from http://www.nier.go.jp/14chousa/14chousa.htm

OECD (2005). Teachers matter: Attracting, developing and retaining effective teachers. Paris, France: OECD.

Pintrich, P. R., Smith, D. A., García, T., \& McKeachie, W. J. (1993). Reliability and predictive validity of the Motivated Strategies for Learning Questionnaire (MSLQ). Educational and Psychological Measurement, 53, 801-813.

Renkl, A., Mandl, H., \& Gruber, H. (1996). Inert knowledge: Analyses and remedies. Educational Psychologist, 31, 115-121.

Rychen, D. S., \& Salganik, L. H. (Eds.). (2003). Key competencies for a successful life and well-functioning society. Cambridge, MA: Hogrefe \& Huber.

Shulman, L. S. (1986). Those who understand: Knowledge growth in teaching. Educational Researcher, 15, 4-14.

Shulman, L. S. (1987). Knowledge and teaching: Foundations of the new reform. Harvard Educational Review, 57, 1-23.

Uesaka, Y., \& Manalo, E. (2017). How to address students' lack of spontaneity in diagram use. In E. Manalo, Y. Uesaka, \& C. A. Chinn (Eds.), Promoting spontaneous use of learning and reasoning strategies: Theory, research, and practice for effective transfer (pp. 62-76). London: Routledge.

Uesaka,Y., Fukaya, T., \& Ichikawa, S. (2017). Strategies for achieving deep understanding and improving learning skills: New approaches to instruction and lesson study in Japanese schools. In Yip, M. (Ed.), Cognition, metacognition and academic performance: An East Asian perspective (pp. 101-121). New York: Routledge. 
$\Longrightarrow$ Taylor \& Francis Taylor \& Francis Group http://taylorandfrancis.com 